УДК 621.039 .56

DOI https://doi.org/10.32838/2663-5941/2019.3-1/36

\title{
Чорнофостова К.В.
}

Одеський національний політехнічний університет

\section{Лисюк Г.П.}

Одеський національний політехнічний університет

\section{ПІДВИЩЕННЯ ЯКОСТІ РЕГУЛЮВАННЯ РІВНЯ В БАЦІ ДЕАЕРАТОРА ЕНЕРГОБЛОКУ АЕС ІЗ ВВЕР-1000}

У статті розглянуто П- та ПІ-регулятори для регулювання рівня в баиі деаератора енергоблоку АЕС із ВВЕР-1000. Отримано графіки перехідних прочесів. Зроблено висновки про доречність використання П- та ПІ-регулятора. В тепловій схемі атомної електростаниії з реактором типу ВВЕР-1000 застосовується деаератор типу ДП-3200/185А. Як відомо, вакуум у конденсаторі сприяє проникненню в його паровий обсяг деякої кількості повітря. Відомий вплив кисню на протікання корозійних процесів. Також наявність перепаду тисків у конденсаторі між середовищами викликає незначний перетік охолоджуючої води в конденсуючий пар при дефектах трубок. 3 иим пов'язана поява в конденсатному тракті хлоридів, бікарбонатів, карбонатів і кремнієвої кислоти, які збільшують електропровідність і сприяють утворенню вільної вуглекислоти, що є корозійно-активним агентом. 3 циих причин на енергоблоках застосовується термічна деаерачія.

Ключові слова: деаератор, термічна деаерачія, корозія, конденсат, математична модель, перехідний прочес, показники якості, структурна схема.

Постановка проблеми. Принцип роботи деаератора заснований на залежності розчинності газів від температури води. У разі підвищення температури води вміст розчинених у ній газів зменшується, а в разі досягнення водою температури насичення дорівнює нулю [1, с. 103].

Термічна деаерація (дегазація) в деаераторі відбувається таким чином: основний конденсат надходить у верхню частину деаераційної колонки і зливається вниз на горизонтально-розташоване сито, а потім проходить водонаправляючий лист і барботажний пристрій. За час руху вниз основний конденсат нагрівається паром, що надходить у нижню частину колонки, до температури насичення при цьому тиску. Основна частина гріючої пари конденсується під час нагрівання води, а надлишок його разом із виділеними 3 води газами відводиться 3 верхньої частини колонки в атмосферу або на ежектори турбіни. Деаерована вода надходить у бак-акумулятор, де відбувається додаткове виділення газів, що не встигли виділиться в деаераційній колонці або були захоплені струменями води.

Аналіз останніх досліджень і публікацій. Відомо, що автоматичне регулювання деаератора здійснюється за рахунок управління витратою гріючої пари, яка подається в деаераційну колонку, а вже управління рівнем деаерованого конденсату, який надходить у бак-акумулятор, здійснюється за допомогою добавки хімочищеної води.
В реальних умовах не завжди вдається досягти необхідної якості деаерації води, і кількість газу в деаерованій воді, яка отримується на виході 3 деаератора, значно більше необхідних значень. I саме це призводить до збільшення корозії всередині обладнання.

Тому підвищення якості регулювання рівня в баці деаератора є необхідною мірою задля попередження корозійних процесів, які знижують термін роботи обладнання та призводять до великих витрат на заміну його компонентів.

Постановка завдання. Метою роботи є підвищення якості регулювання рівня в баці деаератора енергоблоку AEC із ВВEР-1000 за рахунок заміни П-регулятора на ПІ-регулятор.

Для досягнення поставленої мети необхідно вирішити такі задачі:

1. Виконати синтез математичної моделі АСР.

Виведемо рівняння динаміки рівня в деаераторі з витрати конденсату.

Початкові дані:

$\mathrm{F}_{3}=9,3 \mathrm{~m}^{2}$ - площа дзеркала конденсату;

A $=915,2$ кг $/$ м $^{3}$ - щільність конденсату;

$\mathrm{L}=2200 \mathrm{м}-$ номінальний рівень;

$\Delta \mathrm{P}=0,69$ Мпа - перепад тиску на теплообміннику;

$1 / 4=0,62$ - коефіцієнт витрати клапана;

$\mathrm{S}_{\mathrm{kл}}=0,033 \mathrm{~m}^{2}-$ прохідний перетин клапана;

$\mathrm{M}_{\mathrm{n}}=68 \frac{\mathrm{K \Gamma}}{\mathrm{c}}-$ витрата гріючого пару. 
Скористаємося рівнянням збереження маси конденсату:

$$
\mathrm{dm} / \mathrm{dt}=\boldsymbol{M}_{n}-\mathcal{M}_{\kappa},
$$

где $\mathrm{m}$ - маса конденсату в підігрівачі;

$\boldsymbol{M}_{n}, \boldsymbol{M}_{\kappa}$ - масова витрата пару і конденсату.

Уявімо масу конденсату через обсяг і щільність:

$$
\mathrm{m}=\mathrm{V}^{*} \rho .
$$

Своєю чергою:

$$
\mathrm{V}=\mathrm{F}_{3} * \mathrm{~L} \text {, }
$$

где $\mathrm{F}_{3}$ - площа дзеркала конденсату;

$\mathrm{L}$ - висота рівня конденсату.

Будемо вважати, що площа дзеркала конденсату незмінна по висоті:

$$
\mathrm{F}_{3}=\text { const. }
$$

Перепишемо (1) з урахуванням (2) i (3):

$$
\frac{\mathrm{dF}_{3} \rho \mathrm{L}}{\mathrm{dt}}=\mathrm{M}_{\mathrm{n}}-\mathrm{M}_{\mathrm{K}}
$$

або

$$
\frac{F_{3} \rho d L}{d t}=M_{n}-M_{K},
$$

Для усталеного режиму, коли $\mathrm{dL} / \mathrm{dt}=0$, маємо:

$$
0=\mathcal{M}_{n 0}-\mathcal{M}_{\kappa 0},
$$

Уявімо змінні L, ${M_{n}}_{n}, M_{\kappa}$ У вигляді суми сталих значень і відхилень:

$$
\begin{aligned}
\mathrm{L} & =\mathrm{L}_{0}+\Delta \mathrm{L}, \\
M_{n} & =M_{n 0}+\Delta{m_{n}}_{n}, \\
\mathrm{M}_{\mathrm{K}} & =\mathrm{M}_{\mathrm{K} 0}+\Delta \mathrm{M}_{\mathrm{K}},
\end{aligned}
$$

Підставив (6)-(8) в (4) і віднявши (5), маємо:

$$
\mathrm{F}_{3} \rho \frac{d \cdot \mathrm{L}}{\mathrm{dt}}=\Delta \mathrm{M}_{\mathrm{n}}-\Delta \mathrm{M}_{\mathrm{K}},
$$

Перепишемо отримане рівняння у вигляді:

$$
\frac{\mathrm{d} \Delta \mathrm{L}}{\mathrm{dt}}=\left(\frac{1}{\mathrm{~F}_{3} \rho}\right) \Delta \mathrm{M}_{\Pi}-\left(\frac{1}{\mathrm{~F}_{3} \rho}\right) \Delta \mathrm{M}_{\mathrm{K}},
$$

Інтегруючи (10) з урахуванням нульових початкових умов, отримаємо інтегральне рівняння:

або

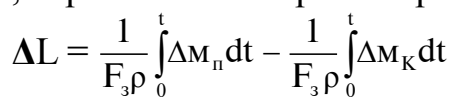

$$
\begin{gathered}
\Delta \mathrm{L}=\mathrm{k}_{1} \int_{0}^{\mathrm{t}} \Delta \mathrm{M}_{\Pi} \mathrm{dt}-\mathrm{k}_{1} \int_{0}^{\mathrm{t}} \Delta \mathrm{M}_{\mathrm{K}} \mathrm{dt}, \\
\text { де } \mathrm{k}_{1}=\frac{1}{\mathrm{~F}_{3} \rho},
\end{gathered}
$$

Передатна функція теплообмінника по каналах витрати пари:

$$
\mathrm{W}(\mathrm{s})=\mathrm{k} / \mathrm{s},
$$

Таким чином, теплообмінник за рівнем конденсату за наявності насоса на стоці за допомо- гою одного з каналів впливів $\left(\mathrm{M}_{п}\right.$ або $\left.\Delta \mathrm{M}_{\mathrm{K}}\right) \epsilon$ астатичною, інтегральною ланкою.

Для інтегральної ланки вираз для кривої розгону за рівнем L має вигляд:

$$
\Delta \mathrm{L}=\mathrm{k}_{1} \Delta \mathrm{M}_{\mathrm{\Pi}} \Delta \mathrm{t},
$$

де $\Delta \mathcal{M}_{n}$ - обурення по витраті пару;

$\mathrm{t}$-час (незалежна змінна).

Розрахунок:

$$
\begin{gathered}
\mathrm{W}(\mathrm{s})=\mathrm{k} / \mathrm{s} ; \\
\mathrm{W}(\mathrm{s})=-\mathrm{k} / \mathrm{s} ; \\
\mathrm{k}_{1}=\frac{1}{\mathrm{~F}_{3} \rho}=\frac{1}{9,3^{*} 934}=11,5^{*} 10^{-5}
\end{gathered}
$$$$
W(s)=11,5 * 10^{-5} / \mathrm{s} \text { - для пару; }
$$$$
\Delta M_{n}=6,8 \kappa \kappa / \mathrm{c} \text {. }
$$

Під час проектування системи автоматичного регулювання в рівній мірі використовуються як теоретичні, так і експериментальні методи дослідження. Застосування теоретичних методів аналізу i синтезу вимагає попереднього математичного опису системи автоматичного регулювання. Система рівнянь, що описують роботу системи регулювання, називається математичною моделлю ACP [12, c. 56].

Розглянемо властивості деаератора за рівнем води. Власне об'єкт-деаератор є астатичним об'єктом із передавальною функцією $\mathrm{W}(\mathrm{s})=\mathrm{K} / \mathrm{S}$. Як відомо, в енергоблоках АЕС додаткову воду в контур енергоблоку подають не в деаератор, а в конденсатор. Конденсатор також $є$ астатичним об'єктом, в якому рівень стабілізується за допомогою П-регулятора шляхом зміни зливу конденсату 3 конденсатора. Цей конденсат проходить через систему регенеративних підігрівачів і після цього надходить у деаератор. Таким чином, в об'єкт регулювання рівня в деаераторі входять 3 послідовно з'єднані елемента (рис. 1): замкнута АСР рівня в конденсаторі, конденсатопровод із ПНД і власне об'єкт-деаератор.

Оскільки робота АСР рівня в деаераторі розглядається у відхиленнях від сталих значень, приріст витрати конденсату на виході з конденсатора і на вході в деаератор однакові. АСР рівня по каналу «витрата хімочищеної води в конденсатор-витрата конденсату 3 конденсатора» разом із конденсатопроводом із ПНД по каналу «витрата на вході-витрата на виході» описується рівнянням інерційної ланки першого порядку, i деаератор описується рівнянням інтегральної ланки. Таким чином, передавальна функція об'єкта управління описується передавальною функцією виду: 


$$
\mathrm{W}(\mathrm{S})=\frac{\mathrm{K}_{1}}{\mathrm{TS}+1} * \frac{\mathrm{K}_{2}}{\mathrm{~S}},
$$

де коефіцієнт $K_{2}$ характеризує астатичні властивості деаератора.

2. Проаналізувати перехідні процеси та дослідити показники якості перехідних процесів регулювання.

Побудуємо графіки перехідного процесу регулювання рівня в деаераторі з використанням П- та ПІ-регуляторів.

Структурна схема АСР рівня в деаераторі зображена на рис. 2, де:

$\mathrm{Wp}$ (S) - передатна функція регулятора рівня в деаераторі;

$\mathrm{Wpo}(\mathrm{S})$ - передатна функція $\mathrm{PO}$;

$\mathrm{WTp}(\mathrm{S})$ - передатна функція трубопроводу;

Wд(S) - передатна функція деаератора;

Wвп (S) - передатна функція вимірювального перетворювача.

Передатна функція РО:

$$
\mathrm{Wpo}(\mathrm{S})=\mathrm{Kpo}
$$

Коефіцієнт передачі регулюючого органу знайдемо з витратної характеристики РО:

$$
\mathrm{K}_{\mathrm{po}}=\Delta \mathrm{G}_{\mathrm{k}} * \frac{1,2}{100}=150 * \frac{1,2}{100}=9,76 \frac{\mathrm{\kappa \Gamma}}{\mathrm{c} * \% \text { хро }}
$$

Передатна функція ВП:

$$
\mathrm{W} \text { вп }(\mathrm{S})=\text { Квп. }
$$

Як вимірювальний перетворювач використовується Метран-43Ф-ДД-3494-03 із вихідним сигналом 0-5 мА.

Максимальний вимірюваний діапазон зміни рівня живильної води $-1,4$ м. Тоді

$$
\mathrm{K}_{\text {ип }}=\frac{\Delta \mathrm{I}}{\Delta \mathrm{H}_{\max }}=\frac{5}{1,4}=3,6 \mathrm{MA} / \mathrm{M} .
$$

Для регулятора рівня в деаераторі об'єкт по каналу «витрата на вході в конденсатор-рівень на виході 3 деаератора» описується передатною функцією:

$$
\begin{gathered}
\mathrm{k}_{\text {д }}=\frac{1}{\mathrm{~F}_{3} \rho}=\frac{1}{9,3 * 934}=11,5 * 10^{-5} \frac{M^{3}}{{M M^{2} * \kappa 2}^{*}} \\
\mathrm{~W}(\mathrm{~s})=\frac{K_{\partial}}{\left[\left(T_{g m}{ }^{*} s\right){ }^{*} s\right]}
\end{gathered}
$$

Оскільки регулюючий клапан встановлюється на паропроводі на деякій відстані від колонки деаератора, ділянка паропроводу від РО до деа-

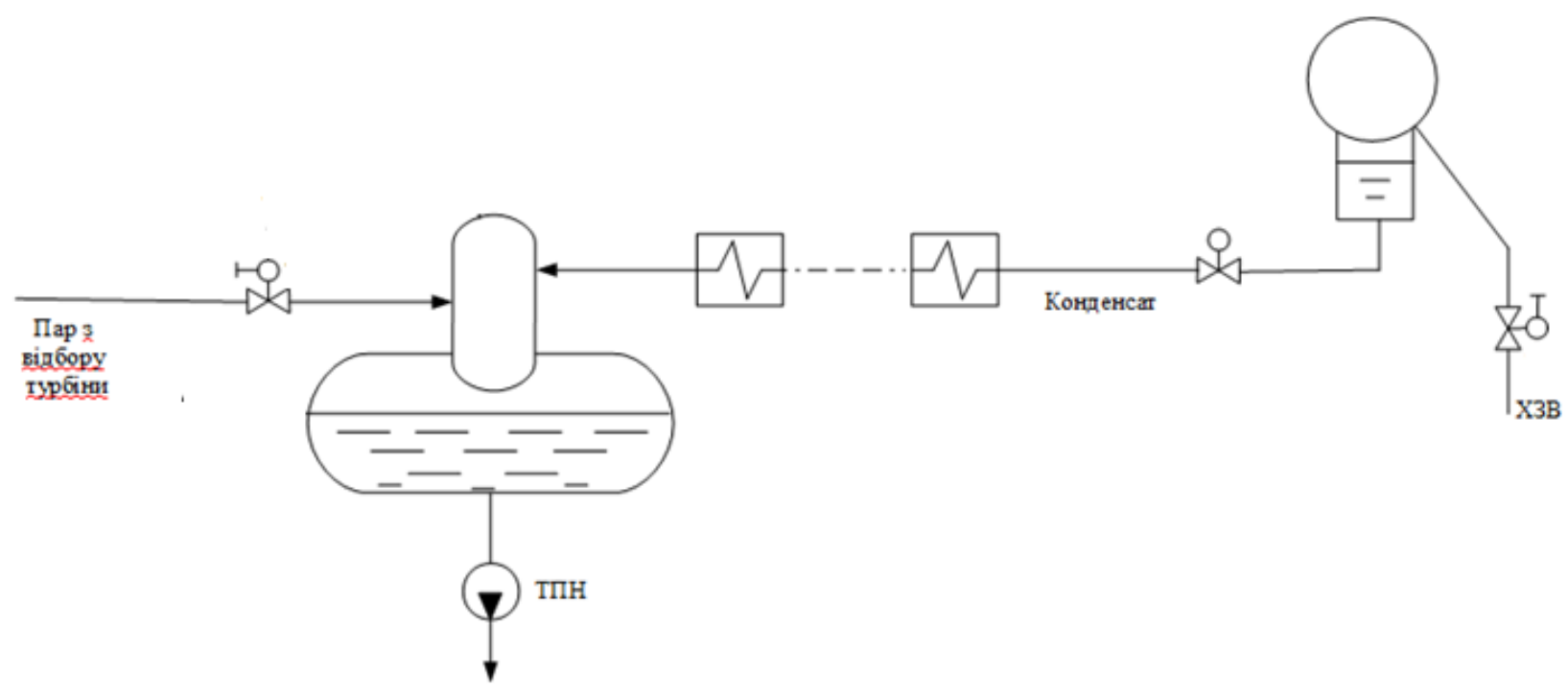

Рис. 1. Принципова схема АСР рівня в деаераторі

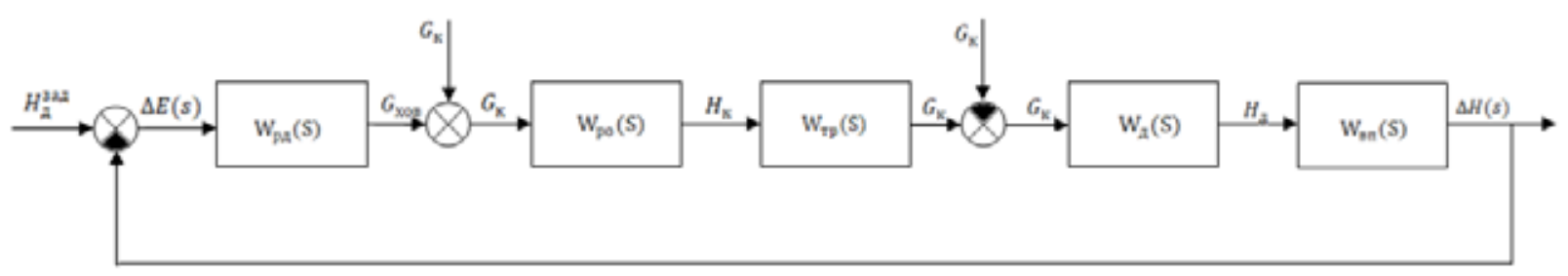

Рис. 2. Структурна схема АСР рівня в деаераторі 
ератора є динамічною ланкою 3 передавальною функцією $W_{n n}(S)$.

де $\mathrm{T}=\frac{1_{\mathrm{rp}}}{\mathrm{v}_{\mathrm{K}}}$.

$$
\mathrm{W}_{\text {пII }}(\mathrm{S})=\frac{1}{\mathrm{Ts}+1},
$$

Відомо, що конденсат у трубопроводі рухається зі швидкістю $0,3 \mathrm{~m} / \mathrm{c}$, а довжина встановлення регулюючого РО від клапана дорівнює 10 м. Отже, отримаємо:

$$
T_{m p}=\frac{10}{0,3}=33,3
$$

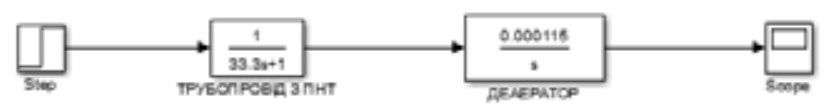

Рисунок 3. Структурна схема об'єкта по каналу Gк-Нд

Побудуємо криву розгону деаератора за рівнем.

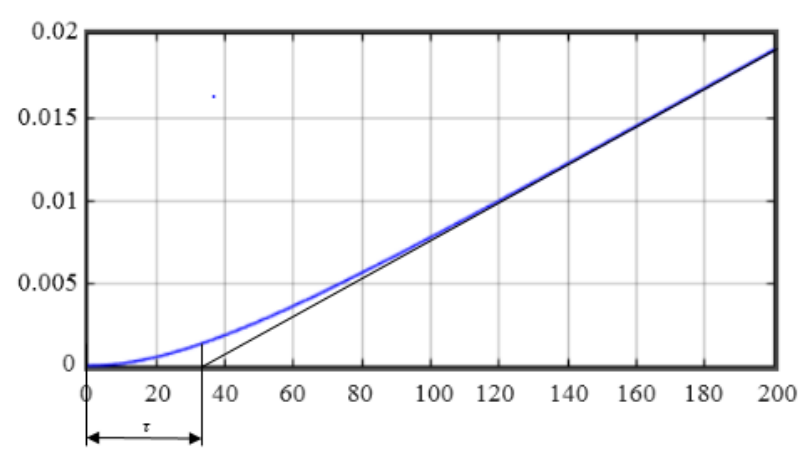

Рис. 4. Крива розгону об’'єкту по каналу Gк-Нд

Крива розгону являє собою пряму похилу лінію з ємнісним запізненням, тобто деаератор за рівнем є нестійким об’єктом.
За кривою розгону визначимо загальний час запізнення $(\tau)$ :

$$
\tau=35 c .
$$

Наступним етапом буде знаходження налаштувань регулятора по каналу Gк-Нд.

Підставимо значення у формули Копеловіча для знаходження настройок регулятора:

- для П-регулятора:

$$
\mathrm{k}_{\mathrm{p}}=\frac{0,7}{\tau / \mathrm{T}}=\frac{0,7}{\frac{35}{33,3}}=0,7
$$

- для ПІ-регулятора $\mathrm{W}_{\text {тр }}(\mathrm{S})$

$$
\begin{aligned}
& \mathrm{k}_{\mathrm{p}}=\underset{\tau / \mathrm{T}}{0,7} \frac{\frac{0,7}{\frac{35}{33,3}}=0,7}{\mathrm{~T}_{д}=3 \tau=3 * 35=105 \mathrm{c}}
\end{aligned}
$$

Але для досягнення системою статичного стану оберемо коефіцієнт, що дорівнює 7.

Структурна схема замкнутої АСР рівня в деаераторі з ПІ-регулятором показана на Рисунку 4, а 3 П-регулятором - на Рисунку 5.

Типовий перехідний процес регулювання може бути зображений у вигляді графіка, де регульована змінна $\mathrm{X}$ після кількох згасаючих коливань приходить до нового збалансованого стану, тобто сталості [12, с. 11].

Перехідні процеси показані на рисунку 7 та рисунку 8.

На рисунку 7 визначені характерні показники якості регулювання:

- $\Delta \mathrm{X} 1(\mathrm{t})=0.17-$ перший максимум відхилення керованої змінної;

- $\Delta \mathrm{X} 3(\mathrm{t})=0.015-$ третій максимум відхилення керованої змінної;

- $\mathrm{t}_{\mathrm{p}}=600 \mathrm{c}-$ час регулювання.

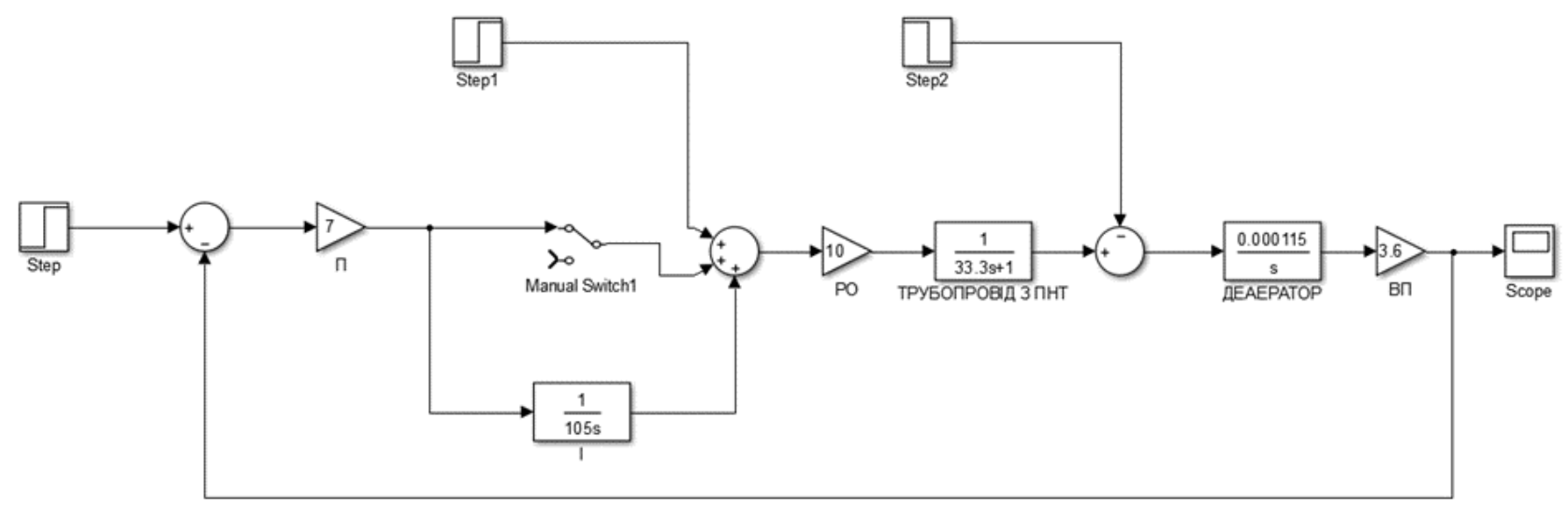

Рис. 5. Структурна схема замкнутої АСР рівня в деаераторі з ПІ-регулятором 


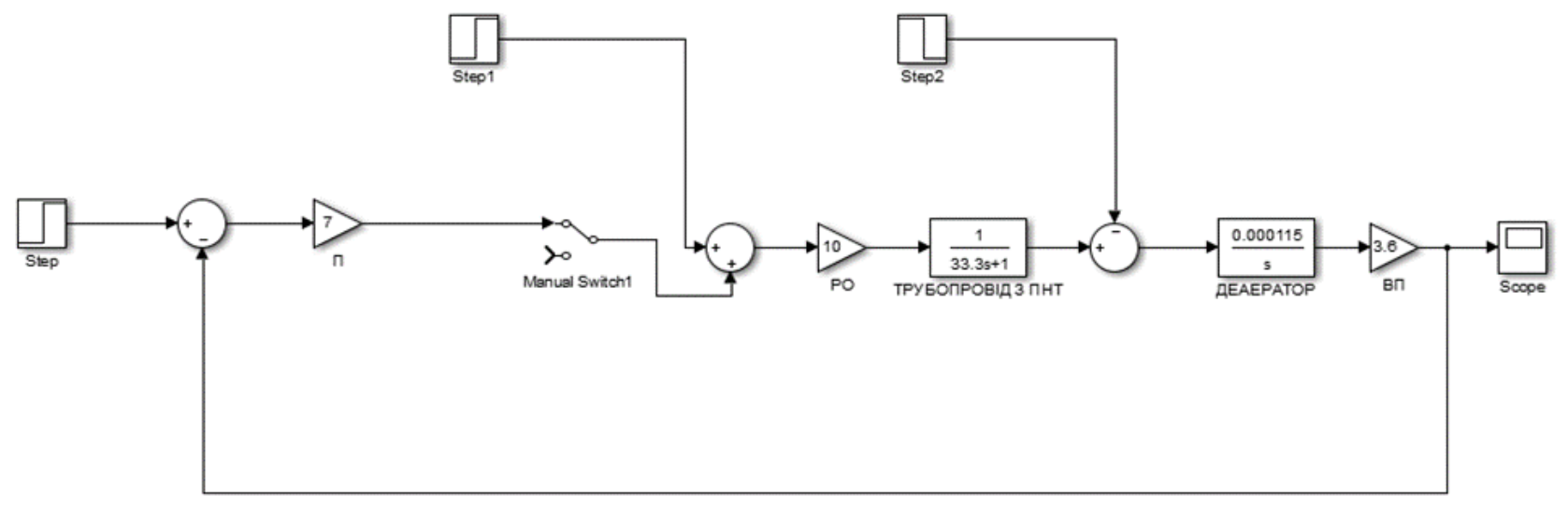

Рис. 6. Структурна схема замкнутої АСР рівня в деаераторі з П-регулятором

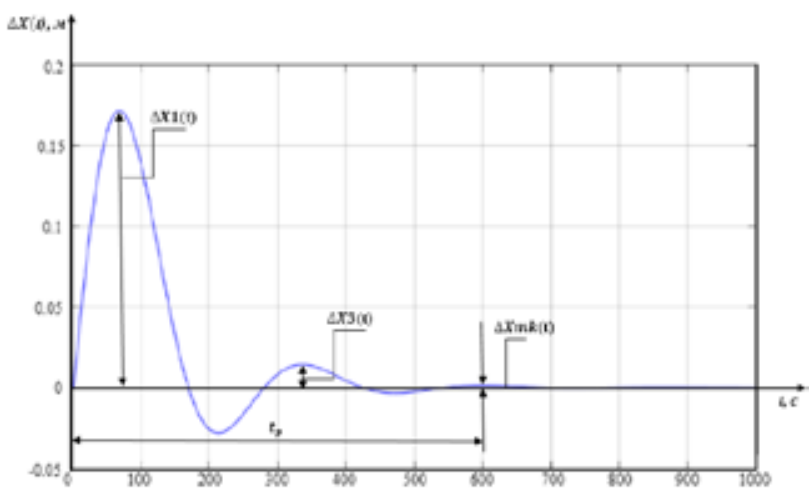

Рис. 7. Графік перехідного процесу регулювання

Крім цих показників, є також показник, який вимагають обчислення:

- показник загасання коливань:

$\Psi=(\Delta \mathrm{X} 1(\mathrm{t})-\Delta \mathrm{X} 3(\mathrm{t})) / \Delta \mathrm{X} 1(\mathrm{t})$

$\Psi=(0.17-0.015) / 0.17=0.91$

За графіком, зображеним на рисунку 8 , можемо знайти кінцеву похибку регулювання $X_{\text {осm }}(\infty)$ при використанні П-регулятора задля регулювання рівня в деаераторі:

$$
\mathrm{X}_{\text {ост }}(\infty)=0.155(\mathrm{M})
$$

За графіками перехідних процесів видно, що у разі застосування П-регулятора процес регулювання рівня в деаераторі матиме статичну помилку, а при застосуванні ПІ-регулятора іï

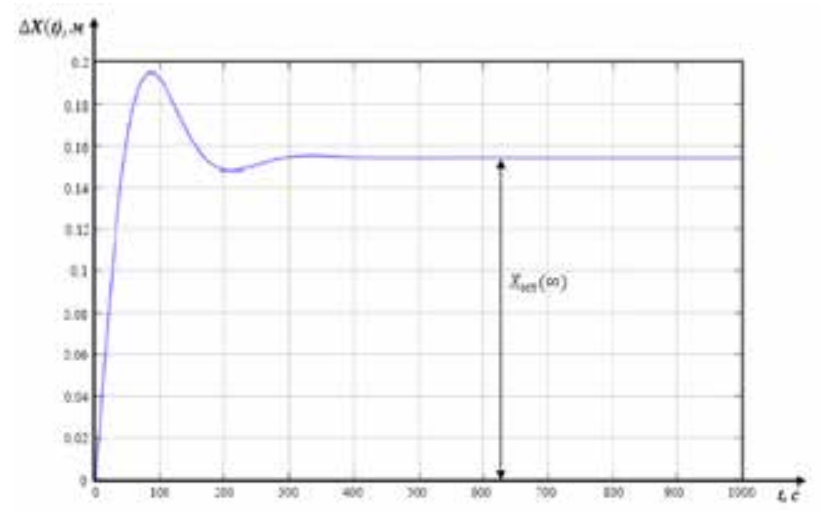

Рис. 8. Графік перехідного процесу регулювання

немає. Відсутність статичної помилки дає змогу отримати кращу якість регулювання.

Висновки. В роботі було виконано синтез математичної моделі АСР рівня в деаераторі. Також було проаналізовано перехідні процеси та досліджено показники якості перехідних процесів регулювання. Отримано графіки перехідних процесів регулювання рівня в деаераторі із застосуванням П- та ПІ-регуляторів. Можна зробити висновок, що з метою підвищення якості регулювання рівня в баці деаератора енергоблоку АЕС iз ВВEР-1000 краще застосовувати ПІ-регулятор, адже у цьому разі відсутня статична помилка. Це дає змогу отримати кращу якість регулювання.

\section{Список літератури:}

1. Beglov K.V., Tsiselskaya T.A. A model of a power unit with VVER-1000 as an object of power control. Odes 'kyi Politechnichnyi Universytet. Pratsi. 2012. № 1(38). P. 99-106.

2. Pelykh S.N., Maksimov M.V. Cladding rupture life control methods for a power-cycling WWER-1000 nuclear unit. Nuclear Engineering and Design. 2011. № 241(8). P. 2956-2963.

3. Babich S.V., Davydov V.O. Objective function for municipal heat supply systems structural optimuzation. Прачі Одеського політехнічного університету. 2015. № 1(45). Р. 134-140.

4. Давыдов В.О., Крылов В.Н., Максимов М.В. Автоматизированная система распознавания. Искусств. интеллект. 2002. № 4. С. 462-469. 
5. Ложечников В.Ф., Михайленко В.С. Методи побудови адаптивних систем управління. Автоматика. Автоматизация. Электротехнические комплексы и системы. 2009. № 2. С. 174-179.

6. Тодорцев Ю.К., Бундюк А.М., Ларіонова О.С. Математична модель контура теплопостачання когенераційної енергетичної установки. Автоматика, автоматизація, електротехнічні комплекси та системи. 2009. № 2. С. 8-11.

7. Брунеткин А.И., Максимов М.В., Бондаренко А.В. Идентификация количественного состава неизвестного газообразного горючего и его продуктов сгорания на основе измеренных технологических параметров процесса сжигания топлива. Вісник Наџіонального технічного університету XПI. Сер.: Енергетичні та теплотехнічні процеси й устаткування. 2014. № 12. С. 131-141.

8. Волошкіна О.О., Плахотнюк О.А., Беглов К.В. Дослідження регулятора концентрації рідкого поглинача енергоблоку АЕС. Автоматизаиія технологічних і бізнес-проиесів. 2015. Вып. 7. № 4. С. 18-24.

9. Бундюк А.Н., Улицкая Е.О. Разработка алгоритма для расчёта статики когенерационной энергетической установки. Холодильная техника и технология. 2013. № 3. С. 34-40.

10. Belova N.A., GP Lisiuk Genetic algorithms application to decide the issue of single-dimensional cutting optimization. Automation of technological and business processes. 2016. № 2. T. 8. P. 4-8.

11. Belova N.A., Lisiuk G.P. Genetic algorithms application to decide the issue of single-dimensional cutting optimization. Automation of technological and business processes. 2016. № 2. T. 8. P. 4-8.

12. Харабет О.М. Вивчення класичної теорії автоматичного управління за допомогою сучасного персонального комп’ютера : навч. посібник. Одеса : Бахва, 2014. 188 с.

\section{ПОВЫШЕНИЕ КАЧЕСТВА РЕГУЛИРОВАНИЯ УРОВНЯ В БАКЕ ДЕАЭРАТОРА ЭНЕРГОБЛОКА АЭС С ВВЭР-1000}

В статье рассмотрены П- и ПИ-регуляторы для регулирования уровня в баке деаэратора энергоблока АЭС с ВВЭР-1000. Получены графики переходных прочессов. Сделаны выводы об уместности использования П- и ПИ-регулятора. В тепловой схеме атомной электростанции с реактором типа ВВЭР-1000 применяется деаэратор типа ДП-3200/185А. Как известно, вакуум в конденсаторе способствует проникновению в его паровой объем некоторого количества воздуха. Известно влияние кислорода на протекание коррозионных процессов. Также наличие перепада давлений в конденсаторе между средами вызывает незначительный переток охлаждающей воды в конденсируюший пар при дефектах трубок. С этим связано появление в конденсатном тракте хлоридов, бикарбонатов, карбонатов и кремниевой кислоты, которые увеличивают электропроводность и способствуют образованию свободной углекислоты, что является коррозионно-активным агентом. По этим причинам на энергоблоках применяется термическая деаэрачия.

Ключевые слова: деаэратор, термическая деаэрация, коррозия, конденсат, математическая модель, переходный процесс, показатели качества, структурная схема.

\section{INCREASING THE QUALITY OF REGULATION OF THE LEVEL IN THE BATTERY OF THE DEAERATOR OF NUCLEAR POWER PLANT WITH WWER-1000}

In the article P-and PI-regulators are considered for adjusting the level in the deaerator tank of the NPP with the WWER-1000. Graphs of transient processes are obtained. Conclusions about the appropriateness of the use of $P$ - and PI-regulators are made. In the thermal scheme of a nuclear power plant with a reactor type WWER-1000 deaerator type DP-3200 / $185 \mathrm{~A}$ is used. As is known, the vacuum in the condenser helps to penetrate into its steam volume of some air. The influence of oxygen on the occurrence of corrosion processes is known. Also, the presence of a pressure drop in the condenser between the medium causes a slight flow of cooling water into the condensing steam at the defects of the tubes. This is due to the appearance in the condensate tract of chlorides, bicarbonates, carbonates and silicic acid, which increase the electrical conductivity and contribute to the formation of free carbon dioxide, which is a corrosive active agent. For these reasons, thermal deaeration is used on power units.

Key words: deaerator, thermal deaeration, corrosion, condensate, mathematical model, transient process, quality indicators, block diagram. 